\title{
RELATIVIZANDO AS IDENTIDADES: VITOR RAMIL E A ESTÉTICA DO FRIO
}

\author{
Valterlei Borges de Araújo* \\ Universidade Federal Fluminense
}

Resumo: Este artigo apresenta os questionamentos levantados no ensaio $A$ estética do frio (2004), escrito e publicado pelo músico e compositor gaúcho Vitor Ramil. No ensaio, o autor expõe algumas diferenças culturais existentes no Brasil, mostrando que a produção cultural sulista tem mais afinidade com os países vizinhos, Uruguai e Argentina, do que com as demais regiões brasileiras. Para Ramil, isso ocorre devido a uma divisão simbólica do país entre Brasil quente e Brasil frio, na qual os produtos culturais que fogem da representação de uma estética quente e tropical, tendem a ficar restritos ao consumo regional. Em paralelo, no decorrer do texto, buscamos analisar como essa estética fria defendida por Ramil é dependente da estética quente para existir enquanto representação cultural. Ainda que havendo divergências e contrastes (de clima, paisagem, território, identidade), esse aparente antagonismo é complementar no que se refere à construção de identidade artística para os músicos dos pampas, funcionando como um jogo de espelhos entre os atores envolvidos.

Palavras-chave: Identidade. Diferença. Canção. Música popular. Estética do frio.

\section{Por uma estética do frio}

Desde o final dos anos 1980, o músico gaúcho Vitor Ramil falava, informalmente, em uma estética vinda do frio: um tipo de produção cultural que, por ser oriunda de uma região geográfica onde predominava o frio, apresentava particularidades que a distinguiam das produções das demais regiões brasileiras.

Essa percepção ficou mais evidente durante seu período no Rio de Janeiro ${ }^{1}$, quando começou a se questionar mais criticamente sobre sua identidade sulista. O choque definitivo que impulsionou seu questionamento aconteceu quando, em um inverno em Copacabana, assistindo ao jornal na TV, uma reportagem mostrava um carnaval fora de época no nordeste, com pessoas aglomeradas, seminuas e pulando atrás de trios elétricos. O âncora do jornal apresentou a festa em tom de normalidade, como se aquela realidade fizesse parte do

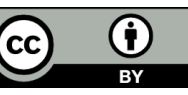

Esta obra está licenciada sob uma Creative Commons - Atribuição 4.0

\footnotetext{
* Doutor em Estudos de Literatura (Literatura Comparada) pela Universidade Federal Fluminense - UFF, Brasil. Autor do livro Novos modelos de produção musical e consumo (Eduff, 2014). E-mail: val.borges@gmail.com.

${ }^{1}$ Vitor Ramil nasceu em Pelotas - Rio Grande do Sul, e morou no Rio de Janeiro de 1986 a 1992. Ainda em 1992, Ramil volta a morar em sua cidade natal, onde vive até o momento.
} 
cotidiano de todos os brasileiros. Na reportagem seguinte, o mesmo âncora mostrou o frio que chegava no sul do Brasil, com geada e pessoas com luvas e agasalhos de lã. O tom desta vez foi de quase incredulidade e de referência a um clima que parecia não fazer parte da nossa realidade, mas sim de uma realidade do hemisfério norte. Ramil, sentiu-se, nesse momento, deslocado dentro de seu próprio país.

A reportagem fez Ramil começar a pensar mais sobre sua real posição, enquanto músico e artista do sul, no cenário cultural brasileiro, e na efetiva contribuição dos sulistas para este país entendido como tropical. O frio e o calor, em sua visão, pareciam dividir o país, porém de forma desigual. Para Ramil, parecia haver uma "estética quente" que conseguia unir os brasileiros - uma estética para a qual "nós do extremo sul contribuíamos minimamente". Dessa forma, "sentíamo-nos os mais diferentes em um país feito de diferenças. [...] Apesar de nossas contrapartidas frias, ainda não fôramos capazes de engendrar uma estética do frio $^{2}$ que revelasse nossa própria face" (RAMIL, 2004, p. 14). Embora essas ideias estivessem germinando na cabeça de Ramil, elas só vieram à tona alguns anos depois, quando Luís Augusto Fischer, professor da UFRGS - e hoje um dos principais pesquisadores sobre as discussões em torno da estética do frio e da música produzida na região da Bacia do Prata - , convidou Ramil a escrever um ensaio sobre o assunto.

A primeira versão do ensaio saiu na revista Nós, os gaúchos, em 1993. Cabe ressaltar que a própria revista, organizada por Fischer, carrega em seu título uma ideia separatista dos rio-grandenses, tal qual a Revolução Farroupilha no século XIX. O lançamento do ensaio chamou a atenção de artistas e pesquisadores sulistas e interessados na discussão da cultura nacional, justamente por lançar um novo olhar investigativo sobre a produção cultural no Brasil. Para nós é notório que a publicação tenha ocorrido em uma revista acadêmica, pois desde então demonstra uma interface de Ramil junto ao mundo acadêmico.

Hoje, Ramil não gosta dessa primeira versão do ensaio, por acreditar que as ideias ainda estavam muito incipientes. Com as discussões surgidas a partir da primeira versão, as ideias foram sendo maturadas e melhor elaboradas. A versão final do texto saiu em livro somente 11 anos depois, em 2004, com o título A estética do frio - Conferência de Genebra. O subtítulo refere-se ao fato de a versão definitiva ter sido apresentada na Suíça durante a conferência "Porto Alegre, un autre Brésil".

As discussões de Ramil foram escritas na forma de ensaio, tanto na primeira quanto na última versão, o que deu liberdade para que pudesse expor suas ideias e sua percepção

\footnotetext{
${ }^{2}$ Desde já, é oportuno antecipar que a expressão "estética do frio" é uma metáfora usada por Ramil para caracterizar a produção cultural surgida no sul do Brasil.
} 
sobre a construção da própria obra e também sobre a produção dos artistas rio-grandenses. Observemos o que diz Adorno sobre essa forma:

\begin{abstract}
O ensaio [...] não admite que seu âmbito de competência lhe seja prescrito. Em vez de alcançar algo cientificamente ou criar artisticamente alguma coisa, seus esforços ainda espelham a disponibilidade de quem, como uma criança, não tem vergonha de se entusiasmar com o que os outros já fizeram. O ensaio reflete o que é amado e odiado, em vez de conceber o espírito como uma criação a partir do nada, segundo o modelo de uma irrestrita moral do trabalho (ADORNO, 2003, p. 16).
\end{abstract}

Em texto publicado no final dos anos 1950, Adorno aponta como o ensaio passava por uma falta de prestígio na Alemanha, apesar de no decorrer da argumentação defender que se tratava de um gênero livre, com pretensões artísticas e que permitia um certo "entusiasmo" que outras formas categoricamente definidas não permitiriam. De modo geral, o ensaísta reflete sobre algum assunto já em pauta ou sobre algum produto cultural já finalizado, apesar de, geralmente, conseguir lançar uma nova análise sobre seu objeto de discussão.

A percepção de Ramil não era inédita. Muito artistas sulistas, incluindo o próprio Ramil, já se questionavam sobre o pertencimento e a localização da produção cultural sulista no cenário brasileiro, pois era inegável que estavam em uma posição desprivilegiada. E aqueles que conseguiam romper essa barreira eram taxados de "vendidos" pelos riograndenses (caso dos irmãos de Ramil, a dupla Kleiton e Kledir). A grande contribuição de Ramil foi justamente organizar essas ideias que de alguma forma já estavam no ar e lançar esse debate no espaço público.

No ensaio, Ramil diz existirem dois Brasis: o Brasil quente e o Brasil frio. O Brasil quente, evidentemente, é aquele estereotipado pela mídia, que é vendido, exportado, e que, de alguma forma, permeia o imaginário coletivo tanto de brasileiros quanto de estrangeiros. $\mathrm{O}$ Brasil frio, por sua vez, é a parte desconhecida e desconectada simbolicamente do restante do país. Trata-se do sul do Brasil, região que costuma ter as estações do ano bem definidas e que possui características climáticas que estão mais próximas de uma realidade europeia do que, propriamente, de uma realidade brasileira, levando-se em conta o imaginário construído sobre o Brasil. Soma-se ainda a maior contribuição dos negros e índios nas regiões norte, nordeste, centro-oeste e sudeste. No sul, há uma maior contribuição dos emigrantes europeus, como os italianos, alemães e polacos.

Essa configuração sociocultural gera uma barreira simbólica que divide o consumo da produção cultural nacional. Ramil entende que tudo que não se encaixa dentro do que é consumido pelo Brasil quente tem uma difícil aceitação no mercado. No entanto, a produção cultural do Brasil frio também traz marcas de brasilidade e, ainda que algumas vezes o 
reconhecimento desse produto esteja mais próximo da realidade dos países vizinhos (Uruguai e Argentina), é possível antever pontes de ligação entre esses dois Brasis. Se existem lacunas entre eles, é notório que também existem pontos de contato que conseguem unificar essa produção a ponto de colocá-la dentro da mesma categoria de produto nacional ou produto brasileiro.

Segundo Ramil, essas contrapartidas frias que a região sul do Brasil produz não conseguem espaço dentro do território nacional de produção e consumo de cultura. Os motivos dessa difícil aceitação são diversos e passam, certamente, pelas características regionalistas e pela ótica comercial que ainda consegue estabelecer e legitimar critérios de valor que são mais difundidos e valorizados do que outros.

A música de Ramil, especialmente dos anos 1990 em diante, é marcadamente influenciada pela tríade cultural Brasil-Uruguai-Argentina, a ponto de afirmar em uma entrevista: essa posição "[...] me levou a refletir sobre a repercussão em mim, e em minha produção artística, do conflito de identidade de ser ou não ser brasileiro, conflito que talvez exista desde sempre no Rio Grande do Sul [...]" (RAMIL, 2008a, 159).

Há ainda outro ponto a ser pensado: trata-se de uma região e de um estado fortemente influenciado pela ascendência europeia (principalmente, italiana e alemã). Não por acaso, Ramil (2004, p. 28) já afirmou: "não estamos à margem de um centro, mas no centro de uma outra história".

Obviamente, a análise histórica é uma importante ferramenta para se entender essa relação, porém a concepção da estética do frio vai além disso: ela tenta problematizar a figura do gaúcho, assim como problematiza assuntos como clima, paisagem, território, regionalismo e identidade - pontos importantes para se entender a relação existente entre o Rio Grande do Sul, o Uruguai, a Argentina e a contextualização da obra de Ramil. O gaucho (em espanhol) ou gaúcho e a milonga passam a ser os ícones centrais da representação dos pampas sulistas da Bacia do Prata. No caso brasileiro, por exemplo, para nos referirmos ao habitante do Rio Grande do Sul, de forma geral, não falamos mais rio-grandense (gentílico de Rio Grande do Sul), mas, majoritariamente, gaúcho (habitante dos pampas).

Algumas dessas referências já aparecem na letra de "Milonga de sete cidades (A estética do frio)":

Fiz a milonga em sete cidades

Rigor, Profundidade, Clareza

Em Concisão, Pureza, Leveza

E Melancolia

Milonga é feita solta no tempo 


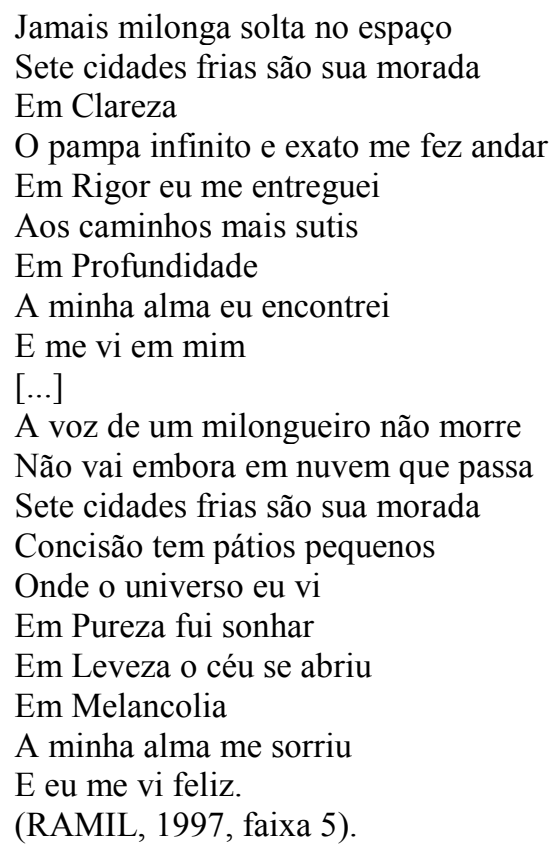

As sete cidades citadas por Ramil, Rigor, Profundidade, Clareza, Concisão, Pureza, Leveza e Melancolia, podem ser entendidas como uma alegoria do autor às características da estética do frio. Suas letras, assim como suas melodias, buscam refletir essas características.

Em entrevista Ramil fala sobre a interpretação da estética do frio, ao dizer que não é devido ao clima que se deve produzir dessa ou daquela maneira. A ideia do frio, nesse caso, é metafórica:

É preciso abstrair para entender o conceito. O frio é algo simbólico na gente. Evidentemente, ele é bastante determinante no nosso comportamento. O clima nos leva a um outro tipo de atividade cultural, de ritmo de vida. Não entanto, não quer dizer que não possamos fazer uma música alegre, por exemplo (RAMIL, 2008b, p. 17).

O frio é, simbolicamente, a característica mais representativa do imaginário da obra de Ramil. A metáfora do frio, legitimada pela publicação do ensaio e pelos desdobramentos das discussões nos meios artístico e acadêmico, se tornou uma marca, inicialmente de Ramil, para posteriormente ajudar a reformular o imaginário sobre o Rio Grande do Sul e recontextualizá-lo no cenário brasileiro. Por conseguinte, a partir da segunda metade da década de 1990, toda uma geração de artistas rio-grandenses, especialmente músicos como Richard Serraria, Oly Jr., Pirisco e Bebeto Alves, entre outros, ajudou a propagar essa reformulação ao se filiarem ao discurso de Ramil, especialmente no contexto platino.

Podemos dizer que a influência regional está presente na obra de Ramil de forma mais subjetiva: este não é o ponto central das intenções do autor. Sua preocupação reside em estruturar uma ambiência que seja representativa de seu universo, porém, sem ser caricatural, 
a ponto de dizer:

[...] para mim, a música gauchesca não nos representa completamente. Em parte, nos representa tanto quanto o rock porto-alegrense. [...] Minhas canções são como meu texto. As pessoas lêem e sempre encontram coisas daqui. E eu não preciso falar de campo ou de cavalo, posso falar de carro e de edifícios. A questão é o contexto (RAMIL, 2008b, p. 17).

Geralmente a difusão da produção se dá a partir de grandes centros urbanos, lugares (ou não-lugares) que têm o poder de reforçar ou legitimar o discurso ou a prática artística adotada a partir de uma posição cultural sólida. Do centro as ideias chegam às zonas periféricas, valendo-se da sua posição no mundo. Ramil, no entanto, rompe esse paradigma ao se posicionar a partir de uma pequena cidade na região fria do Brasil. Essa intenção é ainda mais reforçada quando não se fala da capital, Porto Alegre, mas sim de Pelotas (ou da sua cidade fictícia: Satolep).

Outro ponto tocado n' A estética do frio é a questão identitária. Aliás, é a partir desse questionamento, com a reportagem assistida na TV durante o período no Rio de Janeiro, que a concepção d'A estética começa a se constituir na vida de Ramil. A questão identitária é um dos pontos centrais, talvez o mais importante, levantado na obra.

[...] Muitos de nós, rio-grandenses, consideravam-se mais uruguaios que brasileiros; outros tinham em Buenos Aires, Argentina, um referencial de grande pólo irradiador de formação e cultura mais presente que São Paulo e Rio de Janeiro. A produção cultural desses países nos chegava em abundância, o espanhol era quase uma segunda língua. Muitas palavras, assim como muitos costumes, eram iguais (RAMIL, 2004, p. 14).

O problema é ainda mais aprofundado quando Ramil se pergunta: por que em Montevidéu e Buenos Aires se conhece mais a música produzida no "centro do Brasil" do que a música produzida no sul do Brasil? E por que a música produzida tanto no Uruguai como na Argentina chega mais facilmente ao sul do Brasil, ao passo que não consegue chegar ao “centro do país"? (RAMIL, 2004, p. 17)

A localização de fronteira ocupada por Ramil é essencial para entender a estética do frio, assim como seu posicionamento artístico, que passou a ganhar notoriedade a partir do momento em que se assumiu enquanto um híbrido de produtos local e sulamericano.

Sua obra é pensada dentro do seu macro universo, composto, primeiramente, por Rio Grande do Sul, e depois por Uruguai e Argentina, ou seja, espaços de produção cultural que não são hegemônicos ou que não têm influência no Brasil quente. E como que para circunscrever esse espaço legitimador entre o Brasil quente e o Brasil frio, Ramil cria sua própria cidade: Satolep. Satolep é a cidade imaginária das canções e livros de Ramil, a partir 
da qual ele se permite dialogar de igual para igual com as grandes capitais.

Ramil consegue inverter a ordem do discurso legitimador: o caminho de sua obra, a priori, é periferia-centro. No entanto, por não estar no centro dominador, mas querer dialogar com ele, cria seu próprio centro. Essa dinâmica está diretamente associada à prática dos tempos da globalização da comunicação, na qual as cidades hegemônicas deixam de ser locais centrais de produção e distribuição de informação na medida em que dialogam diretamente com outros inúmeros pólos produtores de informação.

O ideal da estética do frio não é ficar circunscrita à cultura da região Sul, mas, a partir dessa localização e ponto de vista, ultrapassar as barreiras regionais. Os elementos regionalistas acabam tornando-se elementos definidores das particularidades locais, mas sem se fechar em si mesmos. E são esses mesmos elementos que conseguem transitar pelas esferas mais cosmopolitas, se assim podemos chamá-las.

[Vitor Ramil] é um caso precioso para a cultura brasileira também por haver explicitado alguns dos nexos entre os universos brasileiro e platino, os quais, de alguma forma, convergem na cultura cotidiana do Rio Grande do Sul. [...] Até o aparecimento de Ramil praticamente não havia, nem no universo da canção nem no do romance, quem tentasse encontrar os nós, as articulações entre esses dois grandes universos culturais. Depois dele e em grande medida por causa dele, essa condição veio a tornar-se mais comum, mais compreensível de parte a parte (FISCHER, 2013, p. 8).

Por fim, cabe afirmar que $A$ estética do frio não é um manifesto fechado, mas antes uma reflexão de Ramil sobre sua própria produção artística, que acabou repercutindo, inicialmente, no meio artístico e acadêmico do Rio Grande do Sul e, posteriormente, em interessados em discussão de cultura brasileira, além da sintomática repercussão que gerou em outros músicos do Prata como Daniel Drexler, Jorge Drexler, Pablo Grinjot e Kevin Johansen, entre outros.

\section{Jogo de espelhos: A estética do frio, Templadismo, Subtropicalismo e Tropicalismo}

Em entrevista concedida ao jornal argentino Página 12, o músico Daniel Drexler (irmão de Jorge Drexler) fala publicamente sobre o termo Templadismo. Apesar do tom informal da matéria, o Templadismo é apresentado como um desencadeamento direto d' $A$ estétia do frio; e, assim como fez Ramil, o próprio termo cunhado pelos Drexler se contrapõe diretamente ao Tropicalismo ou à ideia de "país tropical". Para Daniel Drexler, o Templadismo (termo derivado do espanhol templado) seria uma espécie de tropicalismo do sul latino-americano ou uma "alternativa cultural frente ao tropicalismo" (DREXLER e MICHELETTO, 2006, s/p). 
Desde então o Templadismo tornou-se o termo utilizado para se referir ao agrupamento musical que começava a surgir no Uruguai. Nesse grupo, outros músicos, à maneira dos já apontados, partilhavam uma gama semelhante de afiliações musicais, não só pela proximidade geográfica mas também pelo tipo de trabalho desenvolvido, o que acabou por intensificar as trocas e as experiências dos músicos da região.

$\mathrm{Na}$ matéria, alguns nomes são citados e o tom de brincadeira sobre o termo Templadismo é reforçado:

Daniel Drexler se inscribe dentro de una escena que también ocupan músicos como Fernando Cabrera, Martín Buscaglia, Kevin Johansen, Lisandro Aristimuño o Vitor [...]. Una escena musical que tiene que ver con lo que, medio en serio y medio en broma, esta gente denominó Templadismo (DREXLER; MICHELETTO, 2006, s/p).

Por sua vez, Ramil afirma, em uma de suas entrevistas", que esse "ismo" lhe causa um certo medo, na medida em que parece carregar um tom definitivo (por isso nunca pensou em usar o sufixo no título de seu ensaio), e que, de certa forma, o Templadismo soa como uma oposição ao tropicalismo, pois não tem interesse em dialogar com diversos estilos musicais, como inicialmente ocorreu com a Tropicália. Pelo contrário, a música que interessa a esses compositores é aquela que carrega um tom mais intimista e que consegue traduzir as características simbólicas dos pampas.

Perguntado sobre o que é o Templadismo erguido em contraposição ao tropicalismo brasileiro, Daniel Drexler explica:

[...] no llega a ser un movimiento, pero sí una herramienta de agitación cultural', [...] mostrando que la cosa no viene tan en chiste. Los templadistas abonan la teoría de que la geografía nos hace sonar de determinada manera: así, si Björk canta 'como partiendo hielo' o la música de Carlinhos Brown despide inevitablemente calor, la llanura induce, en palabras de Drexler, a cierta 'suavidad'. 'El clima influye sobre la identidad y sobre el humor [...] (DREXLER; MICHELETTO, 2006, s/p).

A citação de Daniel Drexler está diretamente relacionada ao que Ramil diz quando afirma que o clima da região é "determinante" no comportamento dos gaúchos. Assim como o frio é uma representação simbólica para Ramil, a planície dos pampas “induz" a um tipo de canção carregada de suavidade, segundo a concepção de Daniel Drexler. Clima e paisagem, portanto, aparecem como alguns dos motes propulsores das reflexões de ambos os compositores. Esse posicionamento se opõe a uma ideologia largamente dominante no Brasil: a de país tropical. "Moro num país tropical", diz uma das canções mais populares de Jorge Ben.

3 Cf. entrevista de Ramil em: <http://catavital.blogspot.com/2009/03/entrevista-vitor-ramil-la-milongaque.html>. Acesso em: 03 abr. 2017. 
Os irmãos Drexler estão entre os músicos que corroboram as ideias de Ramil ${ }^{4}$. Posturas como a dos Drexler, no Uruguai, e de Kevin Joahansen, na Argentina, como veremos à frente, ajudaram a propagação e o desdobramento das ideias d'A estética do frio. Ao mesmo tempo, acabaram ajudando a legitimar o discurso de Ramil nos países vizinhos e no próprio Brasil.

A ideia do Templadismo, ainda muito incipiente e sem um propósito bem definido, chama a atenção mais por sua intencionalidade do que propriamente pela problemática levantada, visto que o termo surge diretamente associado ao pensamento de Ramil e não carrega uma reflexão aprofundada sobre o quê e para quê se propõe, de modo que o entendemos mais como uma corrente uruguaia das ideias d'A estética do frio do que como uma reflexão acerca da música uruguaia.

Por enquanto, é uma proposta pretensiosa, que cria alguns elos com as discussões que vêm sendo estudadas e trabalhadas no Brasil, a ponto de ser difícil dissociar as duas teorias. Em entrevistas, textos e trabalhos publicados, o Templadismo sempre aparece associado a seu genitor gaúcho. Vejamos alguns exemplos:

Em entrevista de Vitor Ramil:

Há uns meses atrás eu te diria logo que $A$ estética do frio não é um movimento, mas atualmente, em função dos seus desdobramentos no Uruguai (onde, a partir dela, os irmãos Jorge e Daniel Drexler formularam o Templadismo) e na Argentina, já não posso dizer o mesmo (RAMIL, 2008a, p. 160).

E em dois trabalhos de Lucas Panitz:

Do outro lado da fronteira platina, os músicos uruguaios, irmãos, Jorge e Daniel Drexler, criam o termo Templadismo - uma alusão ao tropicalismo de Caetano, Gil e Mautner. Templadismo poderia ser traduzido como Subtropicalismo, Temperalismo ou Temperália. De fato no bojo dessa concepção, assim como na estética do frio, está uma característica que acompanha o espaço vivido - o clima e suas estações bem definidas, a presença de verões e primaveras, mas também de outonos e de invernos, e suas respectivas imagens e sensações criadas - como a melancolia, por exemplo (PANITZ, 2008a, p. 7-8).

Daniel Drexler também explica que a denominação Templadismo "[...] surgió de una de esas largas y frecuentes charlas que tenemos con Jorge. Estábamos hablando sobre el tropicalismo, la antropofagia y el libro La estética del frío de Vitor Ramil y a mí se me ocurrió un tanto en broma plantear un 'tropicalismo de las pampas' de los climas templados. Y bueno, se me ocurrió la palabra Templadismo" (Entrevista de Daniel Drexler a Panitz, apud PANITZ, 2008b, p. 37-38).

Na versão ampliada do ensaio A estética do frio, publicada em 2004, Ramil já faz menção ao Templadismo como repercussão de suas ideias no Uruguai. Especialmente depois

\footnotetext{
${ }^{4} C f$. o documentário A LINHA fria do horizonte. Direção: Luciano Coelho. Direção de produção: Christiane Spode. Realização: Linha Fria Filmes. Co-produção: Canal Brasil. 2014. 1 DVD (98 min), son., color., digital.
} 
da publicação d'A estética do frio em livro, torna-se ainda mais notório que existe uma interseção na produção de alguns músicos da região platina.

Ainda que a ideia seja apenas uma ferramenta de "agitação cultural", como defende Daniel Drexler, sua contribuição está no fato de reforçar e legitimar ainda mais as discussões levantadas por Ramil. Ao perceber a repercussão de $A$ estética do frio no Uruguai, Ramil tem a comprovação de que não estava sozinho em suas reflexões, confirmando sua hipótese de não estar à margem de um centro, mas no centro de uma outra história (RAMIL, 2004, p. 28). Especialmente a partir desse ponto, as parcerias e trocas de ideias ganham força e proximidade, de modo que os intercâmbios musicais passam a ficar mais intensos e o produto resultante dessa relação ganha traços que permitem unir essa produção dentro de um mesmo repertório musical.

De forma semelhante, na Argentina, o músico Kevin Johansen cria, na canção intitulada "Milonga subtropical", o termo Subtropicalismo, conforme letra a seguir:

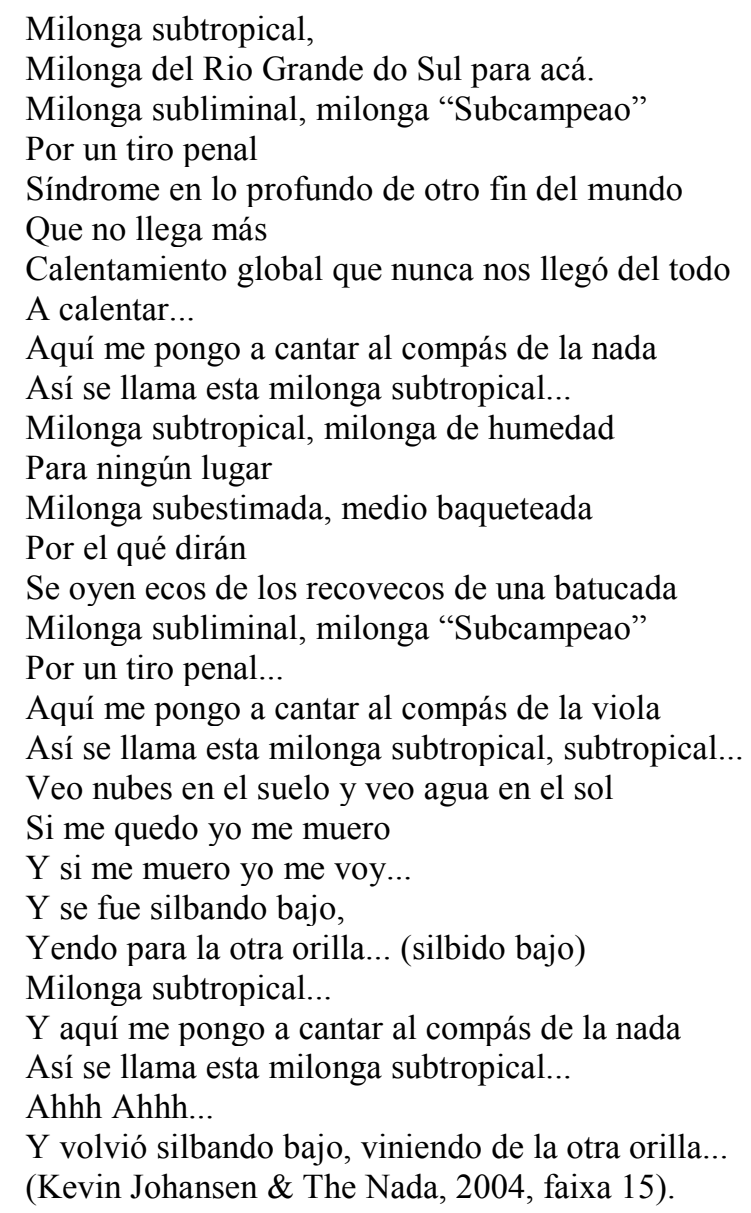

A canção de Johansen parece denotar uma força estética da música tropical na Argentina, pois assim como Ramil ele traz para a cena justamente o que tenta combater. Há uma certa contraposição por incorporação, e o título da canção diz muito sobre isso, 
reforçando a milonga como um produto cultural do clima subtropical.

Assim como acontece com o Templadismo, a ideia do Subtropicalismo, termo novamente associado ao tropicalismo brasileiro, também aparece muito dependente das ideias de Vitor Ramil. É como se Templadismo e Subtropicalismo fossem ideias nascentes d'A estética do frio no Uruguai e na Argentina, respectivamente. A não ser em algumas vagas alusões em reportagens e entrevistas ${ }^{5}$ e em algumas citações pontuais em trabalhos acadêmicos, não se encontra material estruturado a respeito da ideia do Subtropicalismo, de modo que entendemos que o termo acaba servindo, novamente, mais como um elo de ligação com as ideias de Ramil e, especialmente, como um desdobramento d'A estética do frio nos países vizinhos, neste caso, a Argentina.

Vejamos o que diz Panitz:

Kevin Johansen, por sua vez, que se autodenomina um des-generado musical, aquele que não têm gênero musical específico que o possa classificar, mas que desde seu retorno à Argentina em 2000 tem acentuado suas influências do tango e da milonga e seu intercâmbio com artistas brasileiros e uruguaios, usa o termo Subtropicalismo, para se referir ao fenômeno musical do cenário platino. [...] Kevin coloca o sul do Brasil como um lugar comum ao espaço platino, e como definitiva a influência brasileira através do movimento tropicalista [...] (PANITZ, 2010, p. 112).

O trecho de Panitz reflete bem as informações que se têm sobre o Subtropicalismo: trata-se apenas uma ideia inicial que nomeia um suposto movimento musical da Argentina em relação ao universo platino.

Se, por um lado, cabe mais uma vez remeter ao sufixo "ismo" no termo Subtropicalismo, que, novamente, não chega a ser um movimento, mas carrega uma "bandeira" que pode ser afiliada às ideias de Vitor Ramil, por outro, cabe verificar que, tanto na estética do frio como nas suas duas sub-correntes platinas, é recorrente a associação ou a comparação com a Tropicália. Especialmente no caso argentino, a aproximação fica evidente inclusive no nome escolhido por Kevin Johansen. Faz-se necessário, portanto, esclarecer rapidamente o motivo dessa relação.

A Tropicália surgiu nos anos 1967/1968 e, mesmo passados aproximadamente 50 anos desde seu surgimento, ainda é marcante a influência do movimento no universo da canção popular, a ponto de Napolitano e Villaça (1998, s/p) afirmarem que "somos tributários, cultural, política e esteticamente, daquela tradição cultural iniciada entre 1967 e 1968”. Os melhores roqueiros dos anos 80, disse Caetano Veloso, são descendentes do

\footnotetext{
${ }^{5} C f$., por exemplo: http://obviousmag.org/archives/2013/01/do frio para o mundo a estetica da musica platina.html. Acesso em: 03/04/2017.
} 
tropicalismo (VELOSO, 2005, p. 52). O legado da Tropicália na cultura brasileira, especialmente no universo da música de massa, com o rock brasileiro, traz conexões que podem ajudar a entender melhor essa freqüente alusão.

Em Porto Alegre, onde a cena rock ainda é forte, muito foi herdado dos tropicalistas, além da clara e forte afiliação com Buenos Aires e com o rock portenho. O próprio Ramil comenta sobre esse cenário n'A estética do frio, quando diz que em Porto Alegre a diversidade do rock local é de grande vitalidade e, guardadas as devidas proporções, semelhante à da cena de Buenos Aires (RAMIL, 2004, p.15-16) ou ainda quando comenta sobre os embates desencadeados na cena musical porto alegrense:

Roqueiros odiavam nativistas que odiavam roqueiros. As acusações, de lado a lado, podiam ser de que o regionalismo era careta e ultrapassado, ou de que rock destruía as nossas raízes (RAMIL, 2004, p. 17).

Apesar de essa cena também dialogar com o trabalho de Ramil, especialmente no que diz respeito à aproximação de um conceito mais pop (no sentido comercial) em alguns de seus discos, foi a "música local" que acabou definindo sua identidade artística. Sua obra é identificada majoritariamente aos nativistas.

Não é por acaso que tanto Ramil, com A estética do frio, como os irmãos Drexler no Uruguai, com o Templadismo, e Kevin Johansen na Argentina, com o Subtropicalismo, fazem freqüentes referências diretas ao tropicalismo. No caso de Ramil é uma comparação por oposição, pois defende que a estética do frio, ao contrário do movimento tropicalista, pretende se colocar como um movimento intimista, que se volta para seu interior e que não pretende dialogar com outros gêneros que não os gaúchos e platinos. Os irmãos Drexler seguem a mesma lógica. Apenas Kevin Johansen adere mais ao posicionamento adotado pelos tropicalistas, ao ousar dialogar com gêneros pop e latino-americanos.

Apesar de grande apreciador do trabalho de Caetano Veloso ${ }^{6}$, Ramil volta-se cada vez mais para as afiliações locais gaúchas, a exemplo das milongas e das adaptações de poetas regionais em suas composições. O sentido de oposição pode ser percebido também nos nomes adotados nos dois movimentos. A Tropicália ${ }^{7}$, por permitir uma associação direta à ideia de país tropical, aliás, ideia pré-existente inclusive ao próprio tropicalismo; a estética do frio, por tentar apresentar um lado desconhecido do país. A nomeação dos movimentos também reforça a percepção dos dois brasis defendidos por Ramil, o Brasil quente e o Brasil frio.

\footnotetext{
${ }^{6}$ Caetano Veloso canta com Vitor Ramil na canção "Milonga de los morenos", poema musicado de Jorge Luis Borges, no disco Délibáb.

${ }^{7}$ O nome do movimento, Tropicália, surgiu a partir de um penetrável projetado pelo artista plástico Hélio Oiticica.
} 
Se a relação oposicional inicialmente não foi intensiva, de fato ela existe, a ponto de Ramil estar mais próximo da postura dos primeiros anos da bossa nova, na qual a contenção na música e nas atitudes e a introspecção eram marcas importantes. E se no caso da bossa nova a relação com o jazz sempre esteve presente (ainda que em alguns momentos isso não fosse confessado), no caso da estética do frio essa relação direta acontece com a milonga (fato confessado publicamente por Ramil no próprio ensaio).

Portanto, apesar das constantes referências de Ramil e especialmente do grupo do Uruguai e da Argentina ao movimento tropicalista, este acaba servindo mais como um jogo de espelhos ou, em outras palavras, como um outro referencial que contribui para a definição da própria identidade dos artistas platinos, sem o qual a constituição da própria imagem ficaria menos definida.

\section{Referências}

ADORNO, Theodor W. O ensaio como forma. In: . Notas de Literatura I. São Paulo: Duas Cidades; Editora 34, 2003.

DREXLER, Daniel; MICHELETTO, Karina. Una voz con marca de origen. Entrevista de Daniel Drexler cedida a Karina Micheletto. Jornal Página 12, de 15 de junho de 2006. Disponível em: http://www.pagina12.com.ar/diario/suplementos/espectaculos/3-2848-200606-15.html. Acesso em: 02/04/2017.

FISCHER, Luís Augusto. Nesta rua passa o universo. In: RAMIL, Vitor. Songbook Vitor Ramil. Caxias do Sul: Belas-Letras, 2013.

NAPOLITANO, Marcos e VILLAÇA, Mariana Martins. Tropicalismo: as relíquias do Brasil em debate. Revista Brasileira de História, São Paulo, v. 18, n. 35, p. 53-75, 1998. Artigo

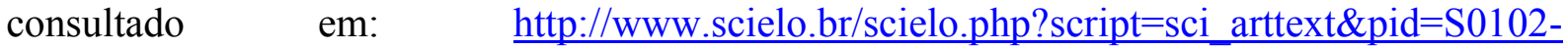
$\underline{01881998000100003}$. Acesso em: 03/11/2017.

PANITZ, Lucas Manassi. A estética do frio e o templadismo: representações da paisagem platina através da música popular. Rio Grande do Sul, 2008a. Disponível em: http://elistas.egrupos.net/lista/encuentrohumboldt/archivo/indice $/ 2441 / \mathrm{msg} / 2499 /$. Acesso em: 02/04/2017.

. As representações do espaço platino na música popular. Trabalho de Conclusão do Curso de Geografia. UFRGS. Rio Grande do Sul, 2008b.

. Por uma geografia da música: o espaço geográfico da música popular platina.

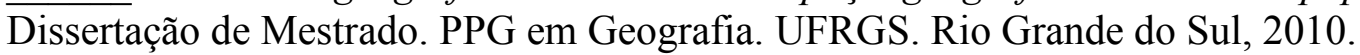

RAMIL, Vitor. A estética do frio: conferência de Genebra. Porto Alegre: Satolep, 2004.

. Entrevista de Vitor Ramil. In: CESARINO, P.; COHN, S.; REZENDE, R. (Orgs.). Azougue (Edição especial 2006-2008). Rio de Janeiro: Beco do Azougue, 2008a. (Azougue 10). p.159-163. 
. A "estética do frio" e a identidade rio-grandense. IHUOnline: Revista do Instituto Humanitas Unisinos. Edição 264. São Leopoldo, p. 16-17, 30 de junho de 2008b.

VELOSO, Caetano. Diferentemente dos americanos do norte. In: . FERRAZ, Eucanaã (Org.). O mundo não é chato. São Paulo: Companhia das Letras, 2005. p. $42-73$.

\section{Discos}

Kevin Johansen \& The Nada. City zen. Sony Music, p. 2004. 1 CD. (ca. 60 min).

Vitor Ramil. Ramilonga. Satolep, p. 1997. 1 CD. (ca. 47 min).

\section{Relativizing the identities: Vitor Ramil and the aesthetic of the cold}

Abstract: This article presents the questions raised in the essay $A$ estética do frio (The aesthetics of the cold) (2004), written and published by the musician and composer from Rio Grande do Sul, Vitor Ramil. In the essay, the author exposes some cultural differences existing in Brazil, showing that southern cultural production has more affinity with neighboring countries, Uruguay and Argentina, than with other Brazilian regions. For Ramil, this happens due a symbolic division of the country between hot Brazil and cold Brazil, in which cultural products that are not related to the representation of a warm and tropical aesthetic tend to be restricted to regional consumption.

In parallel, throughout the text, we seek to analyze how this cold aesthetic defended by Ramil is dependent of the hot aesthetic to exist as a cultural representation. Although there are divergences and contrasts (of climate, landscape, territory, identity), this apparent antagonism is complementary regarding of the construction of artistic identity for the pampas musicians, functioning as a game of mirrors among the actors involved.

Keywords: Identity. Difference. Song. Popular music. Aesthetics of the cold.

Recebido em: 20/04/2017

Aceito em: 24/10/2017

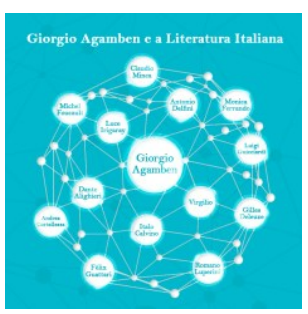

